\title{
HIV/AIDS: KNOWLEDGE, ATTITUDE AND PRACTICE OF SCHOOL ADOLESCENTS IN THE KWAEBIBIREM DISTRICT OF GHANA
}

\author{
H.H. Abruquah and F.Y. Bio \\ University Health Services, \\ Kwame Nkrumah University of Science and Technology, \\ Kumasi, Ghana
}

\begin{abstract}
The study was to assess the knowledge, attitudes and sexual practices relating to HIV/AIDS among adolescents attending both categories of schools. Structured questionnaire was administered by a multistage sampling technique to 600 pupils and students, selected from six Junior Secondary Schools and three Senior Secondary Schools from different towns in the Kwaebibirem district in Ghana. A total of 531 (92.2\%) agreed that sexual promiscuity is on the ascendancy among adolescents. The overall mean age of sexual activity debut among both boys and girls was 11.4 years. High -risk sexual behaviour increased with increasing age and class, and was significantly higher among females than males. Condom use was generally low among the sexually active adolescents. Generally knowledge of STIs among the adolescents was low. Nearly half did not know the origin of HIV/ AIDS, but 83\% knew sexual intercourse as the highest mode of transmission, whilst about 64\% knew HIVIAIDS could be prevented through abstinence and condom use. It was concluded that sexual promiscuity is on the ascendancy among the adolescents, but their knowledge of STIs is generally low. More education is therefore needed to keep them well informed about HIVIAIDS.
\end{abstract}

Keywords: Kwaebibirem, Ghana, STIs, HIV/AIDS, promiscuity

\section{INTRODUCTION}

Teenage sexual activity has increased in many countries around the world during the last two decades (Gage-Brandon et al. 1993). Surveys of premarital sexual activity throughout Africa have found wide variation, ranging from 4 percent in Burundi to over 75 percent in Botswana and Liberia (PRB, 1992). An increasing number of studies addressing adolescent sexuality re- ported early age at first intercourse, high levels of premarital sexual activity and high numbers of sexual partners. Low contraceptive use at first intercourse, and overall lack or infrequent and ineffective use of barrier contraceptives characterises adolescent sexuality (PRB, 1992; Buga et al., 1996; Lagarde et al., 1996). The younger adolescents are when they begin sexual activity, the less likely they are to practice barrier contracep- 
tion thus increasing their risk of Sexually Transmitted Infections (STIs).

Around the world about 333 million new cases of other STIs occur each year (Latif et al., 1986). Each year over 230,000 people die from STDs other than HIV/AIDS (Lauristen et al., 1997). Gonorrhoea and syphilis are the most widely known STIs, but more than 40 others also pose health risk. People are more susceptible to infection with HIV/AIDS if they have another STI (Lauristen et al., 1997) especially an STI that causes genital ulcers, such as chancroid, genital warts, herpes simplex, and syphilis (Komblit, 1993).

The Ghanaian education system may also contribute to early sexual activity and increased trends of STIs including HIV. All Ghanaian children take a placement exam at the end of their Basic education (elementary School). Those who perform well in this exam (about $40 \%$ of Ghanaian students) have the chance to attend very good and academically rigorous traditional Secondary schools that prepare them adequately for University. The less fortunate ones attend the socalled 'mushroom' and 'new' Senior Secondary Schools and have little chance of continuing their education beyond the secondary level. The type of School attended is also associated somehow with social class, with children from affluent homes more likely than those from the lower socio-economic strata to attend the very good secondary schools. Students who attend the Mushroom and new Senior Secondary Schools are more likely to suffer from low self-esteem, a trait that may be related to early sexual activity and increased spread of STIs (personal communication).

The objective of this study, which is unique in its quest to include such a young cohort of adolescents, is to assess the knowledge, attitudes and sexual practices relating to sexually transmitted infections including HIV among adolescents attending both categories of secondary schools. In other words, the survey is to assess their vulnerability and aspects of their behaviour that put them at risk of STIs.

The limitations of the study were its restriction to only the school-going adolescents who constituted only $75 \%$ of the adolescent population in the District and the junior secondary school batch of respondents that covered only the accessible towns.

\section{SUBJECTS AND METHODS}

The study was conducted on a cross section of junior and senior secondary schools in the Kwaebibirem District in the Eastern Region of Ghana in July 2000. The district has a total population of about 293,458 . They are generally farmers, growing cocoa and food crops such as oil palm, plantain, maize and citrus. Civil servants and traders form a much smaller proportion of the workforce. Diamond mining is the main occupation among those in the Akwatia sub-district, thus attracting many young men into the district and increasing promiscuity.

There are 4 Senior Secondary Schools (SSS) and 70 Junior Secondary Schools (JSS), which are evenly distributed throughout the district. There are 2 hospitals, both of which are located in Akwatia with 5 health centres and clinics in the other parts of the district. A structured questionnaire was used in the collection of data. Multistage sampling technique was used to select six Junior Secondary Schools and three Senior Secondary Schools from different towns in the district. All the JSS were co-educational institutions, while the SSS were either girls only, boys and coeducational schools.

Permission for the study was sought from the District Education Directorate, which in turn sought permission form the schools. Informed consent was obtained from the students and pupils as well as from parents. The purpose and nature of the study was explained in detail to the heads and staff of the schools. In each school that agreed to take part in the survey, a teacher who was designated as the coordinator chose the stu- 
dent participants and made arrangements for the focus groups.

\section{Questionnaire}

The questionnaire was administered to a total of 600 participants: 50 from each of the 6 Junior Secondary Schools and 100 from each of the three Senior Secondary Schools.

The questionnaire dwelt mainly on sociodemographic characteristics, sexual activity, attitudes about sexual activity, motivations for engaging in sexual intercourse and knowledge about HIV/AIDS - Seeking behaviour, sources of information and opinion about effective prevention/control of STIs/HIV.

The questionnaire used was developed after discussions with other researchers working on adolescent sexuality regarding STIs/HIV in the district, after reviewing published literature, and with the help of health education experts at the Primary Health Care department of St. Dominic's Hospital. In addition, the suggestions made by the students concerning wording of the questionnaire, after two focus group discussions, one in a JSS and another in an SSS, helped reframe them. The questionnaire and methods of administration were pre-tested once in another JSS, which was not selected for the survey. Only minor changes were made after the pre-testing since the two focus group discussions were used to revise the questionnaire considerably.

Students completed the survey questionnaire in their normal classroom setting in the absence of non-respondent classmates and teachers. Before the students filled the questionnaire, the purpose of the study was re-iterated and they were encouraged to be sincere. To ensure confidentiality, no names were recorded. They were also assured that their responses would not be seen by their friends or teachers. Empty desks were left between respondents, who used a blank sheet of paper to cover their responses.

Where deficient literacy skills were suspected, each question and its possible responses were explained to students by one of the authors (HHA) and were asked to follow along as the questions were read. In addition, most of the questions were close-ended and no skip patterns were used. Data was entered into Microsoft Excel spreadsheet and analysed by EPI-INFO Statistical Programme.

\section{RESULTS}

A total of 576 out of the 600 questionnaire were completed and returned, giving a response rate of $96.0 \%$. The remaining $24(4 \%)$ could not either complete the questionnaire or left for unknown reasons. The age range of the respondents was 11 to 19 years. The mean age of the boys was 16 years, while that of the girls was 15.8 years. Male respondents were $324(56.3 \%)$ with 252 (43.8\%) females. The socio-demographic distribution of the respondents is shown in the Table 1. Parents of most of respondents' had middle or secondary education, with most of the fathers being University graduates. Generally, the fathers' educational levels were higher than that of the mothers. Just about a third of them $177(30.7 \%)$ were from polygamous homes while the rest 399 (69.3\%) came from monogamous homes.

\section{Sexual Activity}

A total of 531 (92.2\%) agreed that sexual promiscuity is on the ascendancy among adolescents and that they had either heard or seen young people below their ages engaging in sexual activity. A total of $210(36.5 \%)$ of the 576 respondents, had been in a relationship before but not necessarily having had sexual intercourse. Of these, 60 (10.4 $\%$ ) reported that they had had only one partner in their lifetime, while $150(26.0 \%)$ had had multiple partners. In all, $195(33.9 \%)$ respondents ( $19.0 \%$ females and $45.4 \%$ males) admitted having ever had sexual intercourse while $63(32.3 \%)$ of the 195 (25\% females and $34.7 \%$ males) had had sexual intercourse a month or less preceding the survey. Of these 195 sexually active ones, 90 $(46.2 \%)$ reported having single partners (66 males and 24 females) whereas $69(35.4 \%)$ re-

12 Journal of Science and Technology, Vol. 28, No. 2, August, 2008 
HIV/AIDS: Knowledge, attitude and Practice of school ...

Abruquah and Bio

Table 1: Adolescents' socio-demographic characteristics

\begin{tabular}{|c|c|c|c|c|c|c|c|}
\hline & \multicolumn{3}{|c|}{ FEMALES (n=252) } & \multicolumn{3}{|c|}{ MALES $(n=324)$} & \multirow{2}{*}{$\begin{array}{c}\text { TOTAL } \\
\text { (576) }\end{array}$} \\
\hline & 11-13 yrs & 14-16 yrs & 17-19 yrs & 11-13 yrs & 14-16 yrs & $17-19$ yrs & \\
\hline \multicolumn{8}{|l|}{ Class } \\
\hline JS 1 & 18 & 21 & 3 & 21 & 21 & 3 & 87 \\
\hline JS 2 & 6 & 30 & 3 & 18 & 30 & 6 & 93 \\
\hline JS 3 & 0 & 27 & 9 & 0 & 24 & 15 & 75 \\
\hline SS 1 & 0 & 39 & 9 & 6 & 9 & 30 & 93 \\
\hline SS 2 & 0 & 24 & 27 & 3 & 12 & 48 & 114 \\
\hline SS 3 & 0 & 0 & 36 & 9 & 9 & 60 & 114 \\
\hline \multicolumn{8}{|l|}{ Family Type } \\
\hline Monogamy & 12 & 111 & 72 & 33 & 78 & 93 & 399 \\
\hline Polygamy & 12 & 30 & 15 & 24 & 27 & 69 & 177 \\
\hline \multicolumn{8}{|l|}{$\begin{array}{l}\text { Father's educa- } \\
\text { tional level }\end{array}$} \\
\hline $\begin{array}{l}\text { None } \\
\text { Primary }\end{array}$ & 0 & 15 & 12 & 3 & 3 & 15 & 48 \\
\hline Primary & 0 & 9 & 6 & 6 & 12 & 6 & 39 \\
\hline $\begin{array}{l}\text { Middle } \\
\text { Secondary }\end{array}$ & 0 & 21 & 18 & 18 & 12 & 18 & 87 \\
\hline $\begin{array}{l}\text { Secondary } \\
\text { Post_Secondary }\end{array}$ & 3 & 21 & 9 & 9 & 51 & 57 & 153 \\
\hline Post -secondary & 6 & 21 & 12 & 9 & 3 & 27 & 75 \\
\hline University & 15 & 54 & 30 & 12 & 24 & 39 & 174 \\
\hline \multicolumn{8}{|l|}{$\begin{array}{l}\text { Mother's edu- } \\
\text { cational level }\end{array}$} \\
\hline None & 0 & 15 & 6 & 6 & 6 & 45 & 81 \\
\hline $\begin{array}{l}\text { Primary } \\
\text { Middle }\end{array}$ & 3 & 12 & 6 & 18 & 18 & 12 & 57 \\
\hline $\begin{array}{l}\text { Middle } \\
\text { Secondary }\end{array}$ & 3 & 30 & 39 & 6 & 18 & 39 & 147 \\
\hline $\begin{array}{l}\text { Secondary } \\
\text { Post_-Secondary }\end{array}$ & 3 & 45 & 12 & 12 & 36 & 36 & 138 \\
\hline Post -Secondary & 12 & 21 & 9 & 6 & 12 & 12 & 78 \\
\hline University & 3 & 18 & 15 & 0 & 15 & 18 & 75 \\
\hline
\end{tabular}

Table 2: Adolescents' Number of Lifetime and Current Partners

\begin{tabular}{lcccccc}
\hline $\begin{array}{c}\text { No. of } \\
\text { Partners }\end{array}$ & Males & Lifetime Partners & \multicolumn{3}{c}{ Current Partners } \\
& & Females & Total (\%) & Males & Females & Total (\%) \\
1 & 39 & 21 & $60(28.6)$ & 66 & 24 & $90(46.2)$ \\
2 & 48 & 12 & $60(28.6)$ & 51 & 0 & $51(26.2)$ \\
33 & 72 & 18 & $90(42.8)$ & 3 & 15 & $18(9.2)$ \\
Total & $\mathbf{1 5 9}$ & $\mathbf{5 1}$ & $\mathbf{2 1 0}$ & $\mathbf{1 2 0}$ & $\mathbf{3 9}$ & $\mathbf{1 5 9}$ \\
\hline
\end{tabular}

* Drawn from the 195 sexually active group. The rest had no partners at the time of the study. 
ported multiple concurrent partners (54 or 36.7 $\%$ of males and 15 or $31.3 \%$ female) (Table 2 ).

Females in the various age groups: $11-13$; 1416 and 17-19 years gave the mean age at which they knew young people engaged in sexual activity as 13.4; 11.9; and 9.8 years respectively, while males of the same age group put them at $11.6 ; 12.1$; and 9.6 years, giving an overall mean age of sexual activity debut of 11.4 years.

High-risk sexual behaviour, such as having two or more concurrent sexual partners, or who use condom occasionally, or have a past or present history of an STD as against low-risk sexual behaviour having only one sexual partner or consistent condom use, was found to increase with increasing age and class and significantly higher among females than males, though greater number of males $(46.2 \%)$ than females $(18.6 \%)$ were sexually active. Also, adolescents from polygamous homes were found to be more sexually active. Moreover, respondents with fathers who had primary, middle, or Post Secondary education had high-risk sexual behaviour than those with fathers who had no education or were either secondary school leavers or graduates.

With mothers' educational background, those whose mothers were of University, Post Secondary education or no education were of low risk status whereas those whose mothers were
Primary, Middle or Secondary education were of high-risk sexual behaviour. The mean age at sexual debut among the females aged 11-13 years was 12.0 , those $14-16,12.5$ and those 17-19, 16.5 years. The ages at debut for the males aged $11-13,14-16$ and $17-19$ years were 12.0 years, 13.9 and 15.5 years respectively. The modal ages of age at debut were 16 and 14 years for females and males respectively.

Generally, females initiated sexual intercourse with partners 2 or more years older than themselves whilst the males had partners their age or younger. Females in the various age groups, 1113 years, 14-16 and 17-19 years averagely had 1, 2 and 4 times sexual intercourse in a month whiles males of all groups had two (2). Only 24 $(6 \%)$ of the sexually experienced adolescents $(6$ females and 32 males) admitted using a condom at their sexual debut (Table 3).

None of the females and males aged 11-13 years used condoms, as well as the males aged 14-16 years. Three females and 32 males aged 17-19 years admitted using condoms at their sexual debut whilst only 3 females aged 14-16 years used condoms. Only $51(26.2 \%)$ of the sexually active adolescents admitted using a condom often [6 $(12.5 \%)$ females and $45(30.6 \%)$ males]. None of the females or males aged 11-13 years admitted consistent condom use; they had not used condoms before! Of the 195 who were sexually ac-

Table 3: Selected measure of sexual activity and condom use at first sexual intercourse among adolescents

\begin{tabular}{llllc}
\hline \multirow{2}{*}{ Measure } & \multicolumn{2}{c}{ Males } & \multicolumn{2}{c}{ Females } \\
\cline { 2 - 5 } & $(\%)$ & $\mathrm{n}$ & $(\%)$ & $\mathrm{n}$ \\
\hline Those reporting sexual intercourse & $(45.4)$ & 324 & $(19.5)$ & 252 \\
Mean age at first sexual intercourse & $(15.0)$ & 147 & $(14.3)$ & 48 \\
Mean difference in years between first partner's age and respondent's age & $(1.3)$ & 147 & $(1.2)$ & 48 \\
Those who used condom at first intercourse & $(26.5)$ & 147 & $(18.6)$ & 48 \\
Those who had sex in less than one month prior to the survey & $(36.7)$ & 147 & $(31.3)$ & 48 \\
Those who used a condom at last sexual intercourse & $(28.6)$ & 147 & $(12.5)$ & 48 \\
\hline
\end{tabular}

14 Journal of Science and Technology, Vol. 28, No. 2, August, 2008 
tive $42(21.5 \%)$ admitted using condoms at their last sexual intercourse [6 (12.5\%) females and $36(24.5 \%)$ males]. Among the inconsistent condom users (144 $(73.8 \%)$ of the sexually active), the common reasons given for non-use were: "reduced sexual enjoyment" [69 (47.9\%)]; "occasional or in frequent sexual exposure" [28 (19.4\%)]; "partner refusal” [31 (21.5\%)]; "injurious to health" [14 (9.7\%)]; and "too young to use it" [2 (1.4\%)]. No one gave the following reasons: "Not aware of its use" or "Inability to afford it."

\section{Knowledge of STIs/HIV}

The respondents, general demonstrated a very low level of knowledge about STIs. Of the 10 questions asked about STIs/HIV, one (1) mark was awarded for every correct answer. A score of between 8 and 10 was considered 'Excellent', $5-7$ 'average' and below 4, 'poor'. In all, 255 $(44.3 \%)$ respondents had 'poor' knowledge about STIs, 237 (41.1\%) had 'average' knowledge and $84(14.6 \%)$ 'Excellent'. The age and sex distributions of their score are shown in Figure 1.

Though all the students had heard about HIV/ AIDS, 138 (24\%) of respondents thought AIDS is a new disease, almost half of the respondents,
285 (49.5\%) did not know its, whilst 135 (23.4\%) thought it originated from Africa.

Knowledge of adolescents on the mode of HIV/ AIDS transmission is shown in Figure 2. The importance of sexual intercourse as a mode of transmission was known by $480(83.3 \%)$ of the respondents with 438 (76\%) agreeing that one could even get infected at first sexual intercourse. However, only $37(6.4 \%)$ attributed its transmission to trans-placental route.

Avoidance of indiscriminate sexual intercourse, in other words, 'abstinence' was the most frequently stated method of prevention of STIs/HIV in general (186 or $32.3 \%$ ), followed by 'condom use' [180 (31.3\%)] and just 'education' [147 (25.5\%)]. Reduction in blood transfusion was the least cited [30 (5.2\%)]. By personal assessment $294(51 \%)$ of respondents felt their chances of acquisition of HIV/ AIDS, were low (177 males and 117 females). One hundred and twenty $(20.8 \%)$ said their chances were low (57 males and 63 females); 54 (9.4\%) high; and 108 $(18.8 \%)$ very high.

\section{Preventive and Treatment- Seeking behaviour}

Most respondents 294 (51.0\%) would first tell their partners if they realized they had an STI, whilst $120(20.8 \%)$ would inform their mothers, with only $57(8.9 \%)$ ready to tell their fathers. No

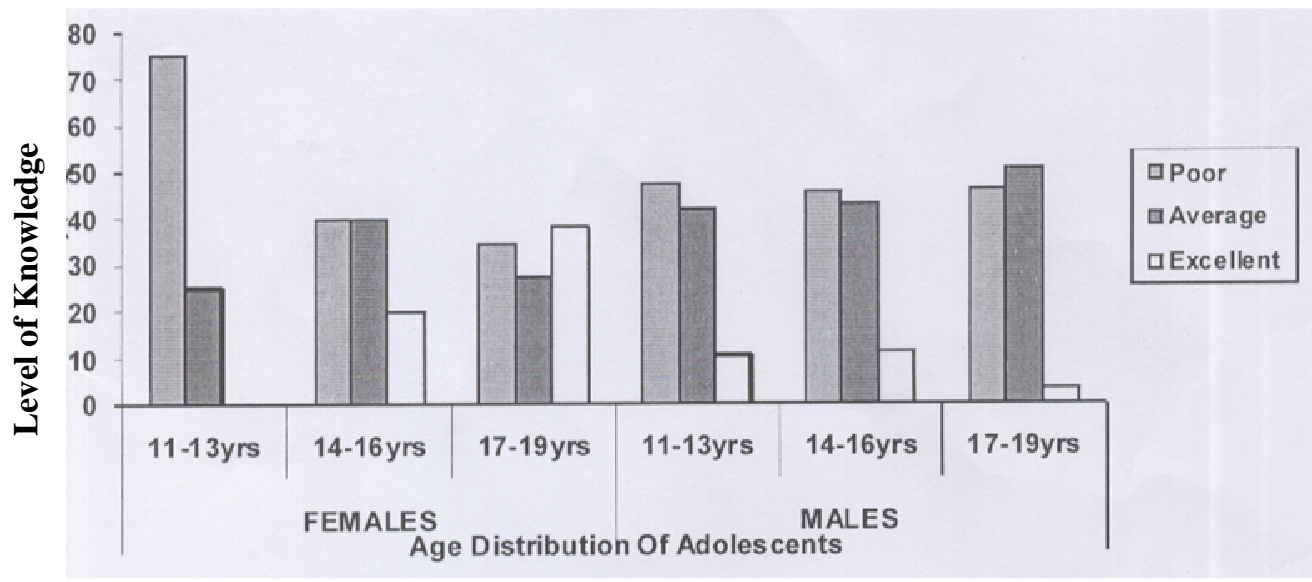

Fig 1: Adolescents' Knowledge of STIs 


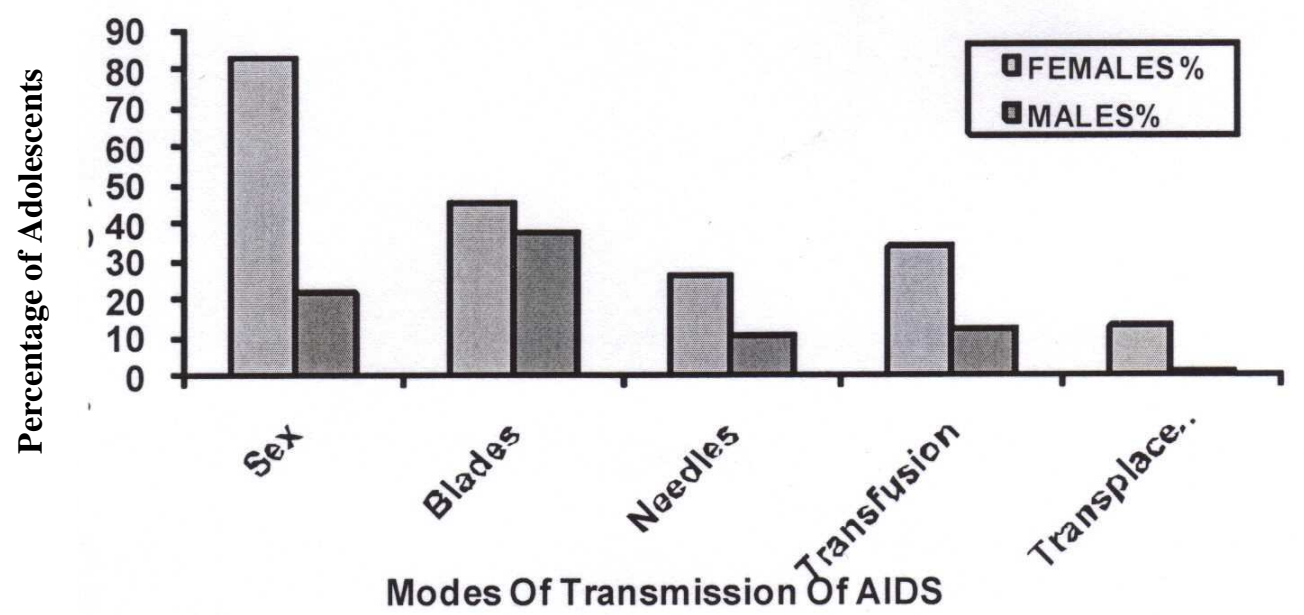

Fig 2: Adolescents' Knowledge of Modes of Transmission of HIV/ AIDS

one was prepared to tell the teacher. A few of them $36(6.3 \%)$ would tell their best friends, 18 $(3.1 \%)$ mentioned their sisters with 9 (1.6\%) mentioning their brothers as the likely persons to know first should they realize they have an STI. However, $48(3.1 \%)$ would not tell anyone about it, while $66(11.5 \%)$ would rather spread it if they discovered they had an STI.

Of the 195 who were sexually active only 27 (13.8\%) of them had once had an STI, with one seeking for treatment from a herbalist, 6 from the Drug store (Pharmacy), 2 from the Private Doctor, 14 from the hospital while 4 never sought for treatment.

Most 393 (68.2\%) of them would however seek treatment from the hospital should they contract an STI, 108 (18.8\%) mentioned a Private Doctor, $54(9.4 \%)$ the Drug Store (Pharmacy), 9 $(1.6 \%)$ the herbalist with $72(2.1 \%)$ going No where. The reasons given for their choice of sources of treatment included 'Confidentiality' (33.7\%), 'speed of cure' (20.7\%), 'speed of service delivery' (8.3\%), 'just prefer that' (12.5\%), 'low cost' (0.9\%). However 49 $(8.5 \%)$ 'did not know' about any source of treatment.

\section{DISCUSSION}

\section{Sexual Activity}

It is most likely that adolescents may be embarrassed to admit their true sexual practices since premarital sex is traditionally and socially unacceptable in our part of the world, and especially even when younger, hence the modal ages at sexual debut of 16 and 14 as opposed to their own opinion of age at sexual debut of 11.4 years.

However, with about one third of the students admitting that they are sexually active, there is the urgent need to equip young people with the correct information about STIs/HIV/AIDS to enable them protect themselves against such infections and to experience safe and healthy sexual development.

With 210 of respondents having been in relationships before (though not necessarily having intercourse), it leaves room for early initiation of sex. The early initiation of sexual intercourse, sexual intercourse with multiple partners and the limited condom use has grave health implications. In addition to STIs/HIV, the adolescents are at risk of unwanted and teenage pregnancies, and its attendant complications of stillbirths, high infant

16 Journal of Science and Technology, Vol. 28, No. 2, August, 2008 
and maternal morbidity and mortality. Some adolescents also procure abortion, while others end up as school dropouts. Even among those who get married, marriage at an early age is never a good idea. For adolescents, abstinence is the surest means of controlling STIs and the HIV/AIDS epidemic.

Premarital sexual activity, like age at sexual debut, varies widely both across and within regions, among both male and female adolescents. For instance, rates of sexual activity among females are $2-11 \%$ in various settings in Asia (Wang, 1996), 12-25\% in Latin America (Komblit, 1993) and 45-52\% in sub-Saharan Africa (Careres, 1995; Biddlecom et al., 2007). In Asia, reported rates of premarital sex are at least five times as high among males as among females and in Latin America, rates are up to twice as high among males (Mpangile et al., 1999). Some of this gender disparity may reflect cultural norms that condone sexual activity among males than among females.

\section{Attitudes about Sexual Activity}

Even before they enter the teenage years, sexual attitudes and behaviours of young Ghanaian adolescents have been significantly shaped by socio-cultural and gender norms that send contradictory messages about sexuality, and impose different standards of behaviour for boys and girls.

The study revealed that girls beginning sexual intercourse earlier than boys was acceptable though the age at sexual debut were pegged at older ages by both sexes. In general, the adolescents expressed negative attitude toward premarital sex, which when strongly reinforced by parental, peer educators, and school curricular will go a long way in curbing promiscuity and STIs/HIV.

\section{Knowledge of STIs}

With increasing age and year of schooling, adolescents' knowledge about STIs/HIV improved but sexual activity also increased. This is not surprising because as adolescents grow up they show more interest in, and discuss reproductive health issues including correct information on sexuality and STIs. Generally, most adolescents did not know about the existence of many other STIs, such as Gonorrhoea and Syphilis, aside HIV/AIDS. Again, most did not know about nonsexual modes of transmission of HIV/AIDS. The implication of this is that they are at risk of contracting STIs/HIV by other modes. The fact that adolescents showed little knowledge in STIs and other modes of transmission of HIV/AIDS is mainly because their main sources of information have been the electronic media and friends, which lack factual content. The accuracy of such information is hitherto woefully inadequate. Adolescence is a stage where factual information on reproductive health matters should be taught. The fact that majority of them did not see themselves as standing a high risk of acquisition of HIV/ AIDS leaves a fertile ground for its spread since these adolescents are unlikely to change their sexual behaviours. This therefore calls for effective programmes to emphasise on the risks to enhance behaviour change.

\section{Preventive and Treatment-Seeking behaviour}

Most adolescents trust in sharing a secret with their partners or mothers than any other person. This is reflected in the results and this is because they believe in these people helping them find a cure and also keeping a secret. Although most of them prefer to seek for treatment from the hospital if they had an STI, the lack of confidentiality and inaccessibility of hospitals makes this unfeasible. This underscores the duty of our health delivery system in controlling STIs and HIV/ AIDS. The alarming perception that people intentionally spread STIs was further reinforced in this study.

\section{CONCLUSION AND RECOMMENDATION}

Though knowledge about STIs/HIV was 'poor' among the adolescents, they knew that the commonest mode of transmission was through sexual intercourse. 
In general, with adolescents' own acceptance of the fact that sexual promiscuity is on the ascendancy even among very young ones, it implies that there is a fertile ground for the spread of STIs and HIV/AIDS among Ghanaian in-school adolescents. This, on the other hand, also leaves us with the hope that adolescents are ready to help combat this menace.

There is therefore the urgent need for school based reproductive health education programmes to improve knowledge, inculcate the right attitudes, and promote behaviours that prevent the transmission of STIs/HIV. There must be a national policy to increase STI/HIV awareness, knowledge, prevention and treatment among young people in Ghana, for the future of our country depends solely on them!

\section{ACKNOWLEDGEMENT}

The authors are grateful to the staff of the Department of Community Health, School of Medical Sciences, Kwame Nkrumah University of Science and Technology, Kumasi, the staff of St. Dominic's Hospital, Akwatia, and to all the heads of the Junior and Senior Secondary Schools, the teachers who served as coordinators and the students who offered to participate in the study.

\section{REFERENCES}

Biddlecom, A.E., Munthali, A., Singh, S., Woog, V. (2007). Adolescents' views of and preferences for sexual and reproductive health services in Burkina Faso, Ghana, Malawi and Uganda. Afr J Reprod Health; 11(3):99-100.

Buga, G., Amoko, D., Ncayiyana, D.J. (1996). Adolescents' sexual behaviour knowledge and attitudes to sexuality among Schoolgirls in Transkei, South Africa. East Afr Med J; 73(2): 95-100.

Caceres, S. (1995). Sexual behaviour of adolescents at Department of Lambayegue and risk of sexually transmitted Disease/HIV infection, Chiclayo. Faculty of Health Sciences, University of Chiclayo, Peru.

Gage-Brandon, A.J., Meekers, D. (1993). Sexual activity before marriage in Sub-Saharan Africa. Soc. Biol; 41(1-2): 44-60.

Komblit, AL. (1993). Sexual models among young and adults convergences and divergences, Buenos Aires. Faculty of Social Sciences, University of Buenos Aires, Argentina.

Laga, M., Manoka, A., Kivuvu, M., Malele, B., Tuliza, M., Nzila, N., Goeman, J., Behets, F., Batter, V., Alary, M. (1993). Non-ulcerative sexually transmitted diseases as risk factors for HIV transmission in women; results from a cohort study. AIDS; 7(1): 95-102.

Lagarde, E., Pison, G., Enel, C. (1996). A study of sexual behaviour change in rural Senegal. J Acquir Immune Defic Syndr; 11(3): 282-7.

Latif, A.S., Mbengeranwa, O.L., Marowa, E., Paraiwa, E., and Gutu, S. (1986). The decentralisation of the Sexually Transmitted Diseases Service and its integration into Primary Health Care. African Journal of Sexually Transmitted Diseases; (2):85-88.

Lauristen, J.L and Swice Good, C.G. (1997). The consistency of self-reported initiation of Sexual activity. Family Planning Perspectives; 29 (25): 215-22.

Mpangile, G.S., Leshabari, MT., Kihwele, DJ. (1999). Induced abortion in Dar-es-salaam, Tanzania: the plight of Adolescents, In Mundigo $\mathrm{A}$, Indriso $\mathrm{C}$ Eds. Abortion in the developing world. Zed books, London:387-403.

Population reference bureau. (1992). Les adolescents en Afrique Sub-Saharienne graphique sur le marriage et la procreation. New York: Population Reference Bureau.

Wang, J (1996). The resolution of pre-marital pregnancy in Shanghai, China. Shanghai, People's Republic of China, Institute of population research, Fudan University. June, 1996.

18 Journal of Science and Technology, Vol. 28, No. 2, August, 2008 